\title{
Study on the corporate behavior under the constraint of energy saving and pollution reduction policy
}

\author{
Fang Zhou \\ Xi Zang Agriculture and Animal Husbandry College \\ E-mail: zhoufang_abc@163.com
}

\begin{abstract}
Based on sample survey of 68 corporations in City D, this study analyzes corporate awareness, behavior, performance and policy needs of energy saving and pollution reduction in the "12th five-year" period, with the help of questionnaires and face to face interview. The empirical analysis of 68 corporations in City D demonstrated that corporate characteristics as scale, ownership, listed situation, target market and national environmental policy had important impacts on corporate energy saving and pollution reduction awareness, behavior and performance. Besides, enterprises in City D hadn't completed the targets set by the central and local government. However, emission reduction policy was better implemented than energy saving policy and it was more difficult to realize energy saving targets. Taking current policy problems into consideration, sufficient preferable policies should be drawn up and binding targets should be allocated differently during " 13 th five-year period.

Keywords: Energy Saving; Pollution Reduction; Corporate Behavior; Corporate Performance.
\end{abstract}

\section{Introduction}

China's economy has maintained an average annual growth rate of $10.6 \%$ in the past three decades with accelerated industrialization and urbanization. As the second largest economy in the world, China maintained a Gross Domestic Product (GDP) of 67.8 trillion RMB in 2015. However, the pressure on energy shortage and pollution emission is increasing along with the rapid economic growth, based on low-cost or free use of natural and environmental resources. In 2015, China's GDP accounted for only $10.5 \%$ in the world, while the proportion of cement, steel, fertilizer and primary energy consumption reached up to $60 \%$, $50 \%, 33.3 \%$ and $20.3 \%$ separately (Figure 1). Energy saving and pollution reduction policy was approved as two legal-bounding targets in the period of "11th Five-Year" (2006-2010): (1) energy saving target-energy intensity per GDP needs to be reduced by 20\%; (2) pollution reduction target - both the emission of $\mathrm{SO}_{2}$ and $\mathrm{COD}$ needs to be declined by $10 \%$. In the period of " 12 th Five-Year" (2011-2015), the pollution reduction targets increased to four: the 
emission of $\mathrm{SO}_{2}$ and COD needs to be declined by $8 \%$, while NH3-N and NOx needs to be declined by $10 \%$. In fact, these targets are ultimately distributed to corporations, which play a significant role in achieving the targets. Therefore, it's of academic importance and practical urgency to study on the corporate behavior under the constraint of energy saving and pollution reduction policy.

However, current studies of energy saving and pollution abatement policy mainly focus on theoretical investigation and policy design in national or provincial level[1-5], ignoring analysis on corporate energy-saving and pollution reduction behavior. Corporate energy-saving and pollution reduction behavior indicates corporate behavioral response in face of external pressure (e.g. market and community) as well as internal pressure (e.g. corporation competitiveness), such as adoption of cleaner production, compliance with emission standards and recycling. Based on sample survey of 68 corporations in City D, this study analyzes corporate awareness, behavior and performance, with the help of questionnaires and face to face interview in the "12th five-year" period. In addition, we assess the corporate policy needs and put forward appropriate recommendations, so as to promote these targets implemented better in the "13th Five-Year" period.

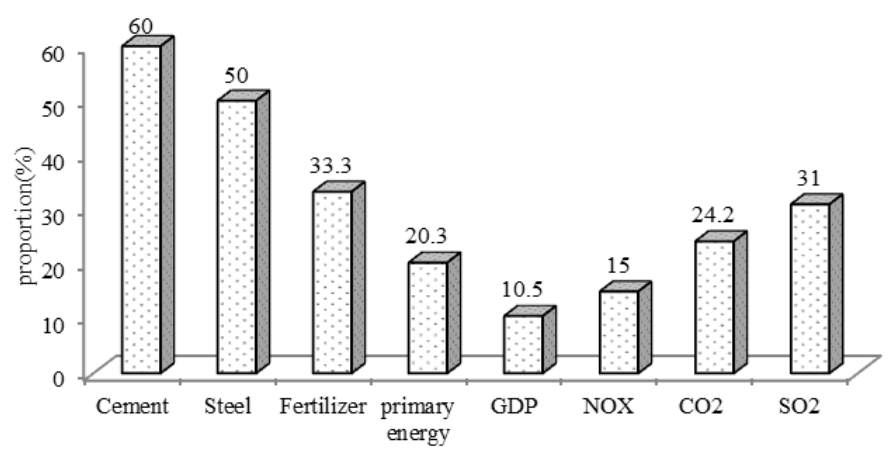

Fig. 1. China's share in the world (2015).

\section{Methods and Data}

This paper selected D as target city, one of China's top 10 cities in terms of GDP. The dominant industries of this city are electronic equipment manufacturing, petro chemistry and machinery production. In short, City D is characterized by a substantial number of industrial enterprises together with various kinds, large proportion of heavy industry and heavy burden of energy-saving and pollution reduction. In order to complete the two legal-bounding targets in the period of "12th Five-Year", Development and Reform Commission of D issued a " comprehensive energy saving and emission reduction work plan", clearly 
pointing out the city's targets: (1) energy intensity per GDP needs to be reduced by $22 \%$; (2) both the emission of $\mathrm{SO}_{2}$ and COD needs to be declined by $18 \%$. These targets are distributed to various enterprises. As a result, D has a strong and typical representative for the study of corporate energy-saving and pollution reduction behavior.

Making use of enterprise database (containing more than 5000 enterprises) of local authorities, 100 corporations were randomly selected in accordance with the sampling rate of $2 \%$. We conducted a questionnaire survey and face to face interviews to managers and staff familiar with related issues in surveyed corporations. The designed questionnaire is divided into the following five sections: the basic corporation information, such as ownership and size, corporate awareness, behavior and performance of energy saving and pollution reduction, the policy needs. After two months of investigation, 68 valid samples were ultimately collected, except for those newly closing down and rejecting the interview. 68 valid samples covered 13 industrial categories, such as petroleum processing and coking, food processing, textile and garment and chemical industry. Figure 2 is a classification of 68 samples, according to their ownership, scale, target market and listed situation.

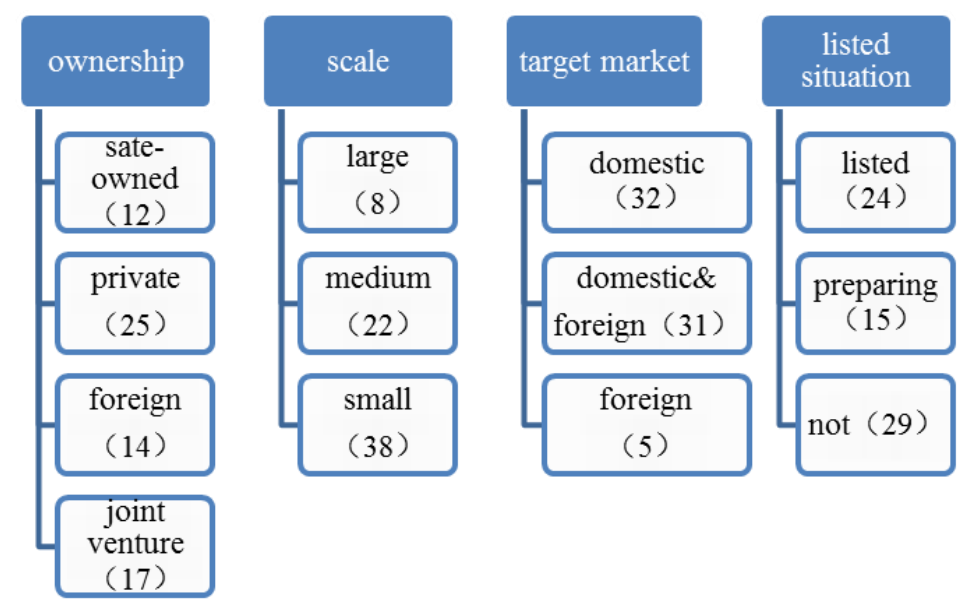

Fig. 2. Basic corporation information of 68 valid samples.

\section{Results and Discussion}

For each corporation, investment demand and marginal cost for energy saving and emission reduction differ a lot. Hence, after analyzing corporate awareness of energy saving and emission reduction as a whole, this part compares corporate behavior and performance differences between energy saving and 
emission reduction. Moreover, policy needs are examined based on problems the existing policies have.

Corporate Awareness. Research found that 54 enterprises (79.4\%) realized the importance of energy saving and pollution reduction, 40 of which thought it count for much. However, most enterprises had negative attitude towards energy saving and pollution reduction policy. 44 enterprises $(64.7 \%)$ considered it would restrict their development, while only 11 enterprises (16.2\%) thought it was conducive to the long-term development. Corporate assessment of the energy saving and pollution reduction targets implemented in "13th five-year" period was basically the same as that in " 12 th five-year" period, except that more enterprises regarded it good to their business(Figure 3). Thus, in the long run, as the corporate environmental awareness grows, the policy will be viewed more objective and neutral. 10 enterprises have always believed that the strict targets contributed to its long-term development, all of which were large and medium-sized, listed, foreign-invested or joint ventures enterprises.

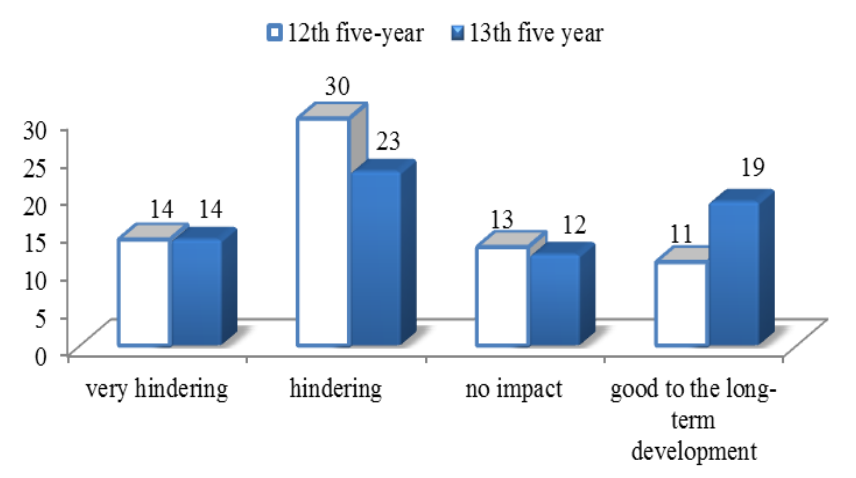

Fig. 3. Corporate awareness of energy saving and pollution reduction policy.

Corporate Behavior. In the 68 valid samples, 53 enterprises $(77.9 \%)$ took actions for energy saving, while 58 enterprises $(85.3 \%)$ responded to pollution reduction. Firstly, these two behaviors have a lot in common: (1) the main driving force is policy pressure, $73.6 \%$ and $84.5 \%$ of the enterprises took passive measures to save energy and reduce pollution under the pressure of the binding targets. (2) Corporate investment in energy saving and pollution reduction takes on partial normal distribution, and the dominant source is the corporations itself, together with a relatively small proportion of government funds. And the government funds are mainly distributed to the large-sized and state-owned enterprise, failing to play an active part in regulating corporate behavior. For example, among 53 enterprises taking action for energy saving, corporate investment of 31 enterprises came from corporations itself, while the rest came from corporations plus government funds (Figure 4). (3) 15 enterprises and 10 
enterprises not responding to the energy saving and pollution reduction policy, are all small-sized and not listed with a vast majority of the private. In the investigation, these enterprises think themselves have minimal impact on the targets. This shows that the government should increase financial support for small-sized enterprises and enhance their environmental awareness.

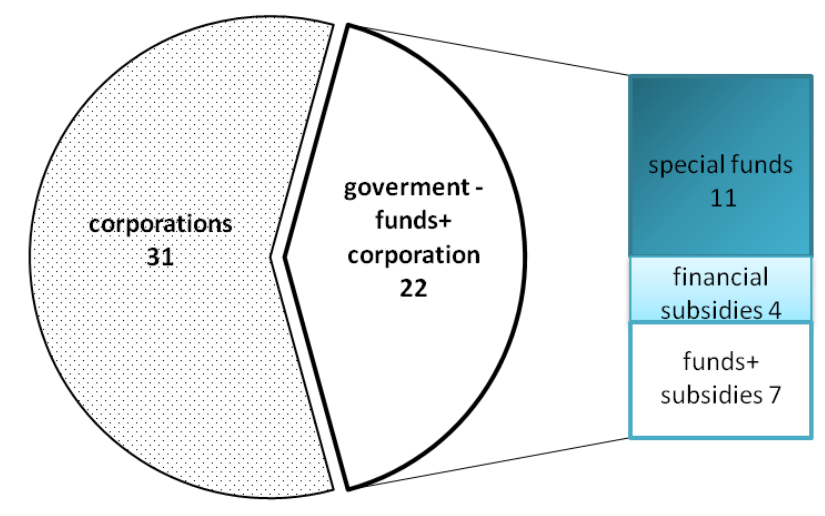

Fig. 4. Source of corporate investment for energy-saving behavior.

Corporate Performance. In this essay, energy saving performance is measured by the decline rate of energy intensity per GDP, while pollution reduction performance by the decreased rate of main pollutants $\left(\mathrm{SO}_{2}\right.$ or $\left.\mathrm{COD}\right)$. In the "11th Five-Year" period, the decline rate of energy intensity per GDP was $13.1 \%$ on average, while decreased rate of $\mathrm{COD}$ and $\mathrm{SO}_{2}$ emission reached separately $9.5 \%$ and $8.7 \%$. Energy saving and pollution reduction performance both lower than the country's targets as well as City D's. The survey demonstrated that enterprises in City D hadn't completed the targets set by the central and local government. However, emission reduction policy was better implemented than energy saving policy and it was more difficult to realize energy saving targets.

In general, corporations responded to pollution reduction more actively than energy saving mainly due to two reasons as follows: firstly, monitoring authorities differ a lot. Development and reform department is responsible for the implementation of energy saving, while itself does not have enforcement power and is difficult to regularly check the progress of corporate energy-saving behavior; environmental protection department is responsible for the implementation of pollution abatement and closely associated with regular sewage charges. Second, main benefits differ a lot. The most important benefit of corporate energy saving behavior is to curtail energy saving expenditures while that of pollution reduction behavior reduce sewage charges. In the background of fluctuating energy prices, enterprises are bound to actively take 
emission reduction actions. Because it will not only directly reduce the corporate sewage charges, reduce its environmental disputes, but also establish a good corporate image.

Policy Needs. Through open interview to the 68 enterprises, we can draw a conclusion that energy saving and pollution reduction policy is an important restriction of corporate behavior. Problems of the current policy faced by enterprises are as follows: (1)Preferential policies of energy saving and pollution abatement are not sufficient and mainly for large-sized and state-owned enterprises. Existing policies mainly rely on command and control methods, economic incentives (such as environmental tax and financial credit) have not effectively implemented. More than $80 \%$ of surveyed enterprises stated that they were lack of investment, technology and information, together with extremely limited policy support. (2) "One size fits all" mode of target allocation is unreasonable. About $75 \%$ of enterprises suggested that existing allocation mode ignored differences of corporate industry, scale and ownership, thus violating the efficiency and fairness principles. (3) Information disclosure is inadequate, as a result, many corporations don't know government's financial support information during the "11th Five-Year" period, which is not conducive to mobilize the initiative of corporate energy saving and pollution reduction behavior.

\section{Main Conclusions and Recommendations}

This study analyzes corporate awareness, behavior, performance and policy needs of energy saving and pollution reduction, on the basis of 68 valid samples collected in the investigation. Conclusions and recommendations are summarized as following:

(1) Corporate energy-saving and pollution-reducing behavior is generated under the integrated action of internal and external driving forces. The empirical analysis of 68 corporations in City D demonstrated that corporate properties as scale, ownership, listed situation, target market and national environmental policy had important impacts on corporate energy saving and pollution reduction awareness, behavior and performance. Most of small-sized, not listed and private enterprises didn't take actions for energy saving and pollution reduction, while majority of large-sized, listed enterprises respond to the targets.

(2) Both similarities and differences exist between corporate energy-saving behavior and pollution-reducing behavior. In general, corporations responded to pollution abatement more actively than energy saving. As a result, emission reduction policy was better implemented than energy saving policy. Besides, owing to energy saving can cooperate with pollution reduction, enterprises can choose a smaller marginal cost approach. 
(3) Taking current policy problems into consideration, energy saving and pollution policies during "12th five-year period should be improved in the following three aspects: First of all, sufficient preferential policies should be drawn up, especially for small-sized enterprises, so as to improve their performance enthusiasms. In addition, binding targets should be allocated in accordance with corporate characteristics, such as industry, scale and ownership, reflecting efficiency and fairness principles. Last but not the least, information disclosure should be improved, mobilizing the initiative of corporate energy saving and pollution reduction behavior.

\section{References}

1. He J.K, Liu B, Zhang A. Analysis of the effect and potential of energy conservation in China. Energy Policy, 2006 (18): 3702-3708.

2. Yang T.Y, Tao Y. Energy Conservation and Discharge Reduction Significance, Approach and Strategy. Ecological Economy. 2008(1): 273276.

3. Ma Z, Wu J, Wei X, Zhang H. L. Lasting Effect Mechanisms based on effectiveness and efficiency. Environmental Protection, 2007(24): 20-22.

4. Wang M., Webber M., Finlayson B. and Barnett J. Rural industries and water pollution in China. Journal of Environmental Management, 2008, 86(4): 648-659.

5. Yuan C.Q., Liu S.F., Fang Z.G. and Wu J.L. Research on the energy-saving effect of energy policies in China: 1982-2006. Energy Policy, 2009, 37(7): 2475-2480. 